International Review of Research in Open and Distributed Learning Volume 21, Number 3

September $\mathbf{- 2 0 2 0}$

\title{
A Qualitative Inquiry of K-12 Teachers' Experience with Open Educational Practices: Perceived Benefits and Barriers of Implementing Open Educational Resources
} Hengtao Tang

University of South Carolina

\begin{abstract}
Teachers in $\mathrm{K}-12$ schools have shown an increasing desire for open educational resources (OER) to ensure all students can learn effectively. OER provide teachers with free access to open-licensed educational resources that they can retain, reuse, revise, remix, and redistribute for personalized instruction. Open educational practices (OEP) have been considered a pathway to reinforce the acceptance and readiness of K-12 teachers to use OER. This research thus showcases a qualitative study that investigates teachers' experiences with OEP. This research explains K-12 teachers' perceived benefits of implementing OER and also discusses their perceived barriers hindering OER usage in $\mathrm{K}-12$ settings. The study also discusses the practical implications of integrating OER in $\mathrm{K}-12$ curriculum.
\end{abstract}

Keywords: open educational resources, open educational practices, K-12 teachers, barriers, benefits, qualitative inquiry 


\section{Introduction}

To date, providing differentiated instruction has been trending for $\mathrm{K}-12$ education in the United States, resulting in teachers' increasing need for educational resources beyond traditional textbooks. To fulfill teachers' needs, implementing open educational resources (OER) in $\mathrm{K}-12$ curriculum can be a viable option (Hilton, Larsen, Wiley, \& Fischer, 2019). OER allow teachers to retain, reuse, revise, remix, and redistribute a rich collection of open licensed resources (Hilton, 2016; Read, Tang, Dhamija, \& Bodily, 2020). Compared with traditional textbooks, open licensed textbooks are more likely to fulfill teachers' needs to provide differentiated instruction (Blomgren, 2018). In addition, research has indicated that classes that implement OER show no harm to course outcome and student motivation when they are compared to classes that use traditional textbooks (Lin \& Tang, 2017; Tang \& Bao, 2020). Therefore, advocating that $\mathrm{K}-12$ teachers implement OER has become necessary for personalized instruction in the United States.

Understanding how teachers perceive technology is critical to advocate for technological integration in K12 classrooms (Granić \& Marangunić, 2019). However, K-12 teachers' voices seem absent regarding their perception of OER (Tang, Lin, \& Qian, in press). Many K-12 teachers in the United States are still not aware of OER despite the widespread \#GoOpen network, an initiative launched by the Office of Educational Technology (n.d.) to encourage OER usage in $\mathrm{K}-12$ school districts (Morales \& Baker, 2018). Without awareness of OER, teachers might lack sufficient knowledge and skills to integrate OER into their teaching (Hassall \& Lewis, 2016) or have a low self-efficacy to do so (Kelly, 2014). To raise teacher's awareness of OER, teacher educators have enabled open educational practices (OEP) to create a contextualized setting for teachers to adapt, produce, and publish OER (Kimmons, 2016; Wiley \& Hilton, 2018). OEP is a broad descriptor for "creation, use, and reuse of open educational resources (OER) as well as open pedagogies and open sharing of teaching practices" (Cronin, 2017, p. 16). Kimmons (2016) indicates that OEP has improved teachers' awareness and understanding of OER, but whether this experience can alter teachers' acceptance of and readiness for using OER in K-12 settings remains unknown (Wiley, Webb, Weston, \& Tonks, 2017). To fill this gap, researchers need to understand how OEP influences teachers' intentions to accept OER as well as any perceived barriers to implementing OER in $\mathrm{K}-12$.

This research thus investigates the actual OEP experiences of U.S. teachers in implementing OER in K-12 classrooms, with a focus on understanding how teachers perceive adopting OER and the perceived barriers they met in implementing OER. Specifically, this research follows the technology acceptance model (TAM) to interpret teachers' acceptance of OER. To understand the barriers teachers encounter in implementing OER, this research refers to prior works by Ertmer, Ottenbreit-Leftwich, Sadik, Sendurur, \& Sendurur (2012) and Hew and Brush (2007). The findings of this research benefit professionals investing in teacher education and open education, especially the effort to promote differentiated instruction in $\mathrm{K}-12$ settings. 


\section{Conceptual Framework}

\section{Technology Acceptance Model}

Numerous models address factors influencing technology acceptance in $\mathrm{K}-12$ settings. The most common one is TAM, proposed by Davis (1989). The original version of TAM considered perceived ease of use (PE) and perceived usefulness (PU) as two fundamental determinants of individual intentions to accept technology, with attitudes (AT) as a mediating variable (Davis, 1989; Granić \& Marangunić, 2019).

PE describes the perceived extent of effort needed to use technology (Davis, Bagozzi, \& Warshaw, 1989). Seminal works on TAM identified PE as the most fundamental determinant, affecting PU and AT regarding technology (Davis, 1989; Granić \& Marangunić, 2019). For K-12 teachers, the primary concern involved in accepting OER is whether they are easy to use (Kelly, 2014). This concern impacted teachers' PU of OER and then determined their intention to use OER (Kelly, 2014). Therefore, reinforcing the ease of using OER is critical to their further implementation in $\mathrm{K}-12$ settings (Kelly, 2014; Tang et al., in press).

PU describes the extent to which individuals perceive that the use of technology can improve their job performance (Davis et al., 1989). For K-12 educators, their intention of accepting technology is highly dependent on whether it can benefit their teaching (Granić \& Marangunić, 2019), including implementing OER (Tang et al., in press).

AT represents individuals' appraisal of behaviors/objects in a dichotomy of positive and negative (Davis, 1989). Attitude is an important predictor of whether teachers intend to accept technology (Granić \& Marangunić, 2019), especially as a variable mediating the influence of PE and PU on teacher intention to implement OER in $\mathrm{K}-12$ classrooms (Tang et al., in press).

\section{Barriers to Technology Integration}

Hew and Brush (2007) found six general barriers that K-12 schools typically face when integrating technology into the curriculum for instructional purposes. These include (a) lack of resources, (b) inadequate knowledge and skills, (c) institutional barriers, (d) attitudes and beliefs, (e) assessment, and (f) subject culture. In particular, these six categories of barriers were further grouped into two overarching types: first-order and second-order barriers. Lack of resources, institutional barriers, assessment, and subject culture are the first-order barriers; and teachers' insufficient knowledge and skills as well as their attitudes and beliefs towards technology are categorized as the second-order barriers (Ertmer et al., 2012; Hew \& Brush, 2007).

The first-order barriers mainly address external factors out of teachers' control. For example, the lack of resources may include one or more of the following: (a) technology, (b) access to available technology, (c) time, and (d) technical support. The institutional barriers may include (a) leadership, (b) school timetabling structure, and (c) school planning. In addition, assessment mainly addresses a perceived tension between using technology and the need to conform to the external requirements of traditional examinations (Hew \& Brush, 2007). In contrast, the second-order barriers mainly concern internal factors within teachers' control. Specifically, they concern teachers' knowledge, skills, attitudes, and beliefs regarding technology use in the classrooms (Ertmer et al., 2012; Hew \& Brush, 2007). 


\section{Methodology}

\section{Research Context and Participants}

This study was conducted through a 16-week, graduate level online course offered by a public university in the southeastern United States. This course asked students to mentor a client on assessing technologyenhanced learning. Students chose clients, but students who were certified teachers had to coach another teacher certified by the same state. The course had six major modules, including (a) Orientation, (b) Measurement, Assessment \& Evaluation, (c) Assessment Planning, (d) Tech-based Assessment, (e) Assessment Implementation, and (f) Reflection.

This course provided summative and formative assessments. The summative assessment was the overarching project, through the course duration, wherein students individually developed an OER-based assessment for the client's technology-enhanced instruction. Students submitted their implementation reports at the end of Module 5. Formative assessments included three major assignments, each of which was geared towards the final summative project. The first major assignment was completed in Module 1. Students reviewed existing assessment instruments used in K-12 settings to familiarize themselves with effective assessment. The second major assignment was an assessment plan in Module 2. In this module, students received instructions on OER and how to search through OER repositories. Then students submitted their plans about how to create/adapt OER-based assessments to efficiently meet clients' needs. The last assignment was reflection notes in Module 6, wherein students responded to questions specifically addressing their experience with OER. Furthermore, students completed several discussion forum activities, with one about students' perceptions of OER and plans to use OER.

A total of 78 students registered this course, 68 of whom were certified teachers and voluntarily participated in this research. Of the 68 participants, $84 \%(N=57)$ were female teachers, $43 \%(N=29)$ taught at elementary school teachers, $28 \%(N=19)$ were middle school teachers, and 29\% $(N=20)$ were high school teachers. Of all the participants, $91 \%(N=62)$ of them had taught in $\mathrm{K}-12$ settings for more than five years. Only five participants had previously used OER, but their usage was limited to reusing resources on Khan Academy. The others never used or heard about OER.

\section{Open Educational Practices}

The open educational practice provided in this course was to give the participants an experience of creating renewable assignments to compare the difference in their acceptance of OER before and after intervention. This intervention was completed in four steps throughout the course. First, the participants reviewed instructions on OER, Creative Commons license, and how to find OER in repositories. Second, the participants adapted OER to develop their own assessments for final projects, following five " $R$ " principles - retain, reuse, revise, remix, and redistribute. Third, the participants implemented the assessments in their client's classrooms and then revised them based on the instructor's and their clients' feedback. Last, they published their OER-based assessments in OER repositories.

\section{Procedures}

Before collecting data, I obtained Institutional Review Board (IRB) approval. 
Data collection. I conducted a phenomenological inquiry to corroborate and extend the quantitative understanding (Creswell, 2007). The phenomenological inquiry (Moustakas, 1994) sought to understand the participants' experience with adopting OER in K-12 curriculum while creating renewable assignments. To understand the participants' experience and perceptions, I collected qualitative data from a triangulated source (Creswell, 2007), including the 68 participants' open-ended questions and their reflection notes.

Open-ended question responses were collected at the end of this course. Eight open-ended questions consisted of five questions about their positive experience with five "R" principles (e.g., Do you have great experience with retaining/reusing/revising/remixing/redistributing OER?), one question asking about challenges with OER (e.g., Do you have any concerns about OER?), and two questions looking into their desired support and suggestions for OER adoptions (e.g., "What support do you think K-12 educators will need to implement OER in their classroom?" and "Do you have any suggestions for the future use of OER in $\mathrm{K}-12$ education?”).

Self-reflection was a required assignment in Module 6 to reflect on their learning experience. A list of questions was provided to structure participants' responses. For example, students were asked to review their experience with OER, reflect any pros and cons regarding using OER in $\mathrm{K}-12$ settings, and plan how to efficiently integrate OER in teaching.

Data analysis. I applied a deductive-inductive coding approach to make sense of the qualitative data (Fereday \& Muir-Cochrane, 2006). Specifically, top-down deductive coding identified patterns geared towards two research questions. These questions became "sensitizing concepts" - the starting point to build up the qualitative analysis and determine the directions of the analysis-of this qualitative inquiry (Bowen, 2006). Thematic analysis was chosen as the inductive approach to elicit the themes from the patterns (Braun \& Clarke, 2006). I recruited a second coder with expertise in OER and teacher education. Specifically, two researchers (myself and the second coder) independently reviewed the qualitative dataset and added initial codes (e.g., "access," "usefulness," "colleagues") to each sentence. Then we met to review sentences with inconsistent codes to reach an agreement on codes. The next step was inductive coding. We worked together to category the patterns and incorporate them into themes (Braun \& Clarke, 2006; Fereday \& Muir-Cochrane, 2006). Constant comparison strategy was applied to ensure the emerged themes "at minimum describe[d] and organizes the possible observations and at maximum interpret[ed] aspects of the phenomenon" (Boyatzis, 1998, p. 161). We identified a total of seven themes (see Table 1 in Appendix).

Validity and reliability. Three measures reinforced the validity and reliability of qualitative findings. First, we triangulated the qualitative data source to avoid a validity threat of self-report bias (Creswell, 2007). Second, constant comparison ensured the reported findings were grounded in the data itself (Patton, 2002). Third, I conducted member checks on the validity of findings directly after the initial data analysis (Merriam, 1998). A summary of preliminary findings was sent to five members and all of them confirmed the findings reflected their experience with OEP. 


\section{Results}

\section{Teachers' Perceptions of Implementing OER after OEP}

Three themes emerged in the findings regarding teachers' perceptions of implementing OER after participating in OEP: (a) participating in OEP empowered teachers' perceived ease of using OER; (b) participating in OEP afforded teachers' perceived usefulness of OER; (c) participating in OEP developed teachers' positive attitudes about implementing OER.

Participating in OEP empowered teachers' perceived ease of using OER. Most participants $(N=40)$ wrote about the ease of using OERs in teaching in their reflection notes and openended question responses. Specifically, I identified three categories: "easily accessible," "no costs," and "no copyright restrictions."

First, many participants insisted the number of available OER and OER repositories made them easily accessible for teachers. Many participants found it easy to find desired resources in OER repositories, such as OER Commons (P15, P22, P42). In particular, participants saw OER repositories as a centralized platform for resources from multiple sources, which allowed participants to avoid moving between platforms back and forth to search for resources (P11).

Through OERs, teachers have so much more information accessible to use in a myriad of ways. (P22, open-ended responses)

I find it extremely easy to find an OER that is useful in my classroom and reusing it. It saves me a lot of time. There are so many great resources out there already made. (P15, open-ended responses)

I chose OER Commons because it was user friendly and searching for OERs seemed to be very easy and accessible. (P11, self-reflection)

They [OER] are easy to reuse, revise, retain, remix, and redistribute. It is accessible to anyone around the world with Internet. (P42, self-reflection)

Second, participants perceived the benefit of the free access to OER, which allowed them to easily use OER. Participants easily found free educational resources in OER repositories, which otherwise might be expensive in copyright-restricted sources (P10). Especially for teachers in school districts with limited budgets, OER were easy to use without the financial burden of purchasing them (P35).

OERs provide great resources for little to no cost to the teacher or school. They can provide the teacher with lessons that include multimedia materials and are easily accessible. (P10, open-ended responses)

Since districts have such limited budgets for materials these days, OERs need to be introduced and modeled as something that can help them provide as much as possible to their students without a hefty price tag. (P35, self-reflection) 
Third, participants preferred the ease of using OER without copyright restrictions. Teachers easily accessed, used, and shared desired resources without concerns about copyrights ( $\mathrm{P}_{5}, \mathrm{P}_{4}$ ). The open licenses provided teachers with the flexibility of using OER, which also improved teachers' perceived ease of using OER (P25).

I have no concerns regarding the use of OERs. I think it is the best kept secret because we are not breaking copyright rules. ( $\mathrm{P}_{5}$ in open-ended responses)

Very easy to do. Made me feel good about using the work knowing 100\% what the copyright was on the resource. (P49, open-ended responses)

There is an opportunity to revise OERs in order to align the learning and assessment with the needs of the audience. The licensing of OERs allows for such flexibility. (P25, self-reflection)

Participating in OEP afforded teachers' perceived usefulness of OER. Most participants ( $N=46)$ discussed their perceptions about how OER improved teaching in K-12 settings. Specifically, I marked four categories: "useful resources for course design," "personalized instruction," "saving teachers' time," and "reciprocal community of educators."

First, participants indicated that OER provided useful resources for course design. For example, teachers were inspired by OER that were relevant to course topics in planning their instruction accordingly (P17). Some teachers referred to OER as a base for their course preparation, which might be especially useful for new teachers (P33). OER were also supplementary resources for teachers, especially when textbooks were not sufficient for course goals (P27).

OERs can also provide teachers with ideas on different ways of teaching various topics. (P17, openended responses)

OERs can help increase student engagement by supplementing traditional teaching mediums, such as books, with digital resources. (P27, open-ended responses)

I wish I had known about OERs when I was an undergraduate right before I began student teaching. I remember feeling so intimidated and had never had any real practice or application with lessons; I had to come up with everything from scratch. (P33, self-reflection)

Second, participants found OER useful for personalized instruction with the afforded flexibility of customizing open-licensed resources. Teachers felt great about being given permissions to revise and remix OER at their discretion ( $\mathrm{P}_{3}, \mathrm{P}_{34}$ ). With OER, teachers also had flexible options of open-licensed multimedia products tailored to students' individualized needs to learn effectively (P26, P66).

The great thing about OERs is that you can change the resources to fit your specific needs. ( $\mathrm{P}_{3}$, open-ended responses)

The advantages of OERs is that you have many ways to differentiate your lessons, with the huge variety of videos, animations, simulations, and text. (P26, open-ended responses) 
The various OER resources have given me ideas to help students of various learning styles. It has given me the resources to meet the needs of all my students (on level, advanced, gifted, and below level). (P34, self-reflection)

One area that I needed to revise with regard to using this assessment before implementing in the future is differentiation. I would like to efficiently integrate OERs that challenge the more intellectually advanced students and promote reflection. This added component would offer more opportunities for enrichment. (P66, reflection notes)

Third, participants agreed that implementing OER saved time in developing instruction and assessment materials. Teachers adapted high-quality OER to meet their classrooms needs rather than creating a new instruction or assessment from scratch (P6, P33).

One pro to OERs is the fact that so many resources are available for use and that can cut lesson prep time drastically. (P33, open-ended responses)

I think the biggest pro to integrating OERs in my assessment project was that there were many resources available that would have taken me a very long time to create. This saved me time while still providing quality materials to the students. (P6, self-reflection)

Fourth, participants perceived that using OER allowed them to collaborate with colleagues worldwide in creating and sharing useful resources. Teachers using OER formed an online reciprocal professional community of colleagues with similar interests and needs ( $\left.\mathrm{P}_{53}, \mathrm{P} 62\right)$. Teachers benefited from collaborating with colleagues who "have already developed successful strategies" to address similar challenges ( $\mathrm{P}_{53}$ ).

By using OERs, you are collaborating with teachers from all over the world. By sharing, creating, and using OERs, I am collaborating with thousands of educators. (P62, open-ended responses)

OERs can serve as a tremendous tool for teachers. They offer a network of other educators that have experienced similar situations and have already developed successful strategies for addressing some of the common challenges in special education. ( $\mathrm{P}_{53}$, self-reflection)

\section{Participating in OEP developed teachers' positive attitudes about implementing OER.}

Many participants $(N=42)$ expressed positive attitudes about implementing OER. Specifically, three categories were identified: "positive experience," "continued implementation," and "agents of change."

More than half of the participants $(N=39)$ had positive experience with implementing OER. Teachers enjoyed searching, using, and sharing OER and developed a positive perception of OER's ease of use and usefulness in $\mathrm{K}-12$ teaching (P33, P37). Producing and sharing OER were perceived as valuable for teachers given the benefits of OER for teaching (P28).

Overall, I find OERs to be a great resource both new and veteran teachers alike. (P33, open-ended responses) 
I enjoyed exploring the online OER website. I had not seen a resource like this and it was really great to see that this is available for teacher use. (P37, open-ended responses)

I am now aware of the valuable resource OERs provide for my instruction My work from this course will be valuable as I share my knowledge of assessment and OERs. (P28, self-reflection)

Many participants indicated their willingness to continue with implementing OER. Teachers planned to use OER and OER repositories frequently in their future teaching (P23, P59). The experience with implementing OER helped improve teachers' expertise in using OER ( $\mathrm{P}_{59}$ ). Furthermore, teachers planned to invest in probing efficient ways to use OER (P6, P59).

I plan to further research OERs for my specific subject area and use them when I can in my teaching. (P6, open-ended responses)

In the future, I plan to use the OER commons to find resources and implement them into my own classroom. (P59, open-ended responses)

I believe this is largely a reflection of the course that I, along with my client, teaches. In the future, it is my goal to strive to adopt more OER assessments into my teaching practices. (P23, selfreflection)

For future purposes, I plan on implementing OERs more frequently. I feel that in using them more often, I will become more comfortable and willing to use OERs in my classroom. I feel that in doing this, it would have helped me effectively integrate OERs into my work. (P59, self-reflection)

Participants $(N=14)$ described their intention of being an agent of change for OER integration in $\mathrm{K}-12$ settings. Participants were willing to contribute to OER repositories by sharing their self-created works (P33). They also planned to help colleagues or any other teachers increase the awareness of OER and provide support and mentoring for colleagues to overcome the barriers (P33, P46). In all, they hoped to become the "transformative force" to advocate for OER usage in the school district or a broader community.

I believe that if more teachers knew about the need for materials, they would be willing to contribute. In the future, I plan to post any material that I have personally created to OER. (P33 in open-ended responses)

I think they will need a lot of support, and I intend to learn more about them and offer support to the teachers in my school and district on them. (P46 in open-ended questions)

Considering the benefits of using OER in the classroom, I hope to be a transformative force at my school to encourage other teachers to use OER to deliver information and assess student learning. (P31 in self-reflection)

I am just beginning to use OERs in my professional work ... I have already started sharing what I have learned with my colleagues and will continue to use them in my instruction. (P55 in selfreflection) 


\section{Teachers' Perceived Barriers to Implementing OER in K-12 Settings?}

Two themes emerged regarding teachers' perceived barriers to OER use in $\mathrm{K}-12$ settings: first-order barriers and second-order barriers.

First-order barriers. Over half of the participants $(N=38)$ discussed the perceived first-order barriers of integrating OER in $\mathrm{K}-12$ education by reflecting on their coaching experience. Four categories emerged: "a lack of quality assurance," "limited time," "unsupportive climate," and "inadequate support."

First, most participants $(N=42)$ were concerned about a lack of high-quality OER fitting their needs. Particularly, participants noted that few OER aligned with the course standards existed for them to reuse in instruction and assessment ( $\mathrm{P} 4, \mathrm{P} 64)$. Participants teaching certain subjects (e.g., special education) and early grades (e.g., K1-5) struggled using OER given limited availability of age- and grade- appropriate resources (P24, P53). Additionally, participants discussed the concerns about validity and sustainability since some OER were not validated by education authorities or appropriately maintained (P17). The unreliable quality of some OER created a barrier that impeded teachers' further implementation of OER in $\mathrm{K}-12$ settings.

When exploring OERs, I would find resources that may be specific to a standard that I teach, but it does not fully cover the required standard that students are supposed to know within my classroom. (P4, open-ended responses)

Most resources I found were too cognitively high for my students, or not age-appropriate for my students. (P24, open-ended responses)

Disadvantages associated with OER include lack of quality control and sustainability issues. Since OER are free, its creators have little to no incentive to ensure the content they share remains relevant, accurate, and accessible. (P17, self-reflection)

I also had difficulty finding appropriate lessons and assessments for high school special education. This is a very common problem with high school special education, as most lessons that are cognitively appropriate, basic reading comprehension for example, is usually at an ageinappropriate level of elementary school. (P53, self-reflection)

There is definitely a lack of good OERs relating to assessment. Finding more rigorous assessment or assessment that relates to performance tasks was much more difficult, especially in the areas of language arts (P64, self-reflection)

Another barrier for participants was that they did not have sufficient time to sift through appropriate OER. Teachers were bombarded with excessive resources and were concerned about whether they had adequate time to prudently look into the resources (P14, $\mathrm{P}_{51}$ ). Allowing teachers sufficient time to search for OER that best fit their needs became a prerequisite for expediting OER adoption in $\mathrm{K}-12$ settings ( $\mathrm{P}_{37}$ ).

Teachers don't have time and need things to be immediately relevant. PD workshops on implementing them into actual lessons [were needed]. (P51, open-ended responses). 
They will need to know they exist. Teachers are bombarded with resources. Education is resource rich, but time poor. It is imperative that teachers know how much this could help them and benefit their instruction. (P14, self-reflection)

I personally believe that we could improve on our usage of OERs. Having more time to explore the world of OERs and finding ones that best suit our needs is the first step. (P37, self-reflection)

Furthermore, participants were challenged by the lack of a positive climate for implementing OER in K-12 schools. Participants $(N=36)$ were concerned about an unsupportive institutional culture of OER usage, as some school districts encouraged teachers to use standardized resources. Other participants $(N=16)$ complained that some OER were disabled by the local school district.

Before OER can make a big impact in K-12 education, teachers and administrators need to have a better understanding about OER. They need to have a solid understanding about how OER can be used to maximize learning for students. (P42, open-ended questions)

The major con of the use of OER was that my school district is discouraging the use of all but "vetted" resources. We are being asked to focus on using materials that have been purchased by the school district, as well as resources supplied by the Department of Education. I find this frustrating and a bit limiting, but it is the current landscape in which I am teaching. (P56, self-reflection)

The cons would be that sometimes it is hard to access some of the sites. Many schools, including my own, have very strict firewalls. They block inappropriate sites, but sometimes appropriate ones are blocked as well out of an abundance of caution. (Participant 29, self-reflection)

Moreover, participants noted that a lack of relevant training thwarted OER usage in K-12 classrooms. Some school districts offered professional development opportunities for integrating OER, but further improvements were needed to increase teachers' awareness of OER and ability to use OER. Particularly for those teachers without exceptional background in technology, they desired effective training to "feel more comfortable to use [OER] with students in the classroom."

The cons are that they should be promoted more in teacher trainings. Schools and counties could save so much money if they learned how to better use these free educational resources in the classrooms (P45, open-ended responses).

Prior to this course, my experience with OERs were limited. While attending several professional developments provided by my district, the topic of OERs had been mentioned, but I haven't expanded my understanding of these resources until now. (P18, self-reflection)

There are a lot of "tech savvy" teachers now in the classroom, but there are a lot of teachers that have a much more difficult time buying in to this new concept. Teachers should be trained in these so they feel more comfortable to use with students in the classroom. (P61, self-reflection)

Second-order barriers. A majority of participants $(N=46)$ described the perceived internal barriers (second-order) impeded implementing OER in $\mathrm{K}-12$ settings. Three categories emerged from the 
analysis including a lack of (a) awareness of OER, (b) proficiency in finding OER, and (c) expertise in integrating OER in teaching.

First, participants reported that they were not aware of OER at all before this course, much less aware of the benefits. Some participants had used OER but did not realize it until attending this course ( $\mathrm{P}_{51}$ ). Participants' low awareness of OER also became a barrier to efficient implementation of it, because they struggled to understand why they needed OER.

At the beginning of the course, I had never heard of the term open educational resource. (P33, openended responses)

Unfortunately, I did not do an excellent job of integrating OERs into my assessment. In fact, what I thought was an OER ended up not being an OER at all. (P34, open-ended responses)

Because I did not feel that I fully understood the intended purpose of OERs at the beginning of the course, it hindered my understanding of implementing an OER into my assessment plan. (P43, selfreflection)

When I first began to research OERs, I was surprised that I had used them in the past but wasn't aware of the terminology. They are a resource. As a teacher, we are bombarded with resources. $\left(\mathrm{P}_{51}\right.$, self-reflection)

Second, participants $(N=39)$ outlined a lack of proficiency in efficiently finding OER tailored to their needs. Participants had difficulty determining whether a resource was open-licensed. Participants also described struggling to narrow down the search to locate appropriate resources from an overwhelming number of resource options. Teachers' insufficient proficiency in sifting through appropriate OER hampered their intention to adopt OER.

Another issue with OERs is figuring out the permissions for a specific resource: what am I allowed to do with a resource once I've found it, and how do I know it's an OER? (P9, open-ended responses)

I am concerned at narrowing down my search. There seems to be so much available that I get overwhelmed. It is easy to get lost. (P12, open-ended responses)

The only concern I have with the use of OER is that there is so much out there that it can be overwhelming. When I search 7th grade equations on one OER site, so many resources came up. I tried to refine my search to find exactly what I needed and there were still a lot of resources to look through. (P26, self-reflection)

Third, many participants $(N=31)$ reported insufficient expertise in adapting and integrating OER in their classroom. Participants had difficulty integrating OER into assessment because of their ignorance of OER (P57). Other participants struggled to efficiently integrate OER because they hoped to find resources that perfectly "match[ed] the idea in [their] head" without any revision or remixing (P27). Moreover, participants found it challenging to develop skills adapting and integrating OER because they needed to be well-versed in content knowledge and instructional design skills. 
Integrating the OERs into my assessment project was one of the most challenging aspects of the course. One reason for this was that I did not have prior experience using OERs before this course. (P57, open-ended responses)

I think my biggest downfall in efficiently integrating OER's into my work was having a lesson plan in mind and trying to find an OER that matched the idea in my head. However, I found that it's much more efficient to look for ideas within an existing OER and create extensions off them rather than try to make the OER fit my mental image. (P27, self-reflection)

The integration of an OER into the assessment plan was not as seamless as anticipated. It became necessary to develop a deeper understanding of OERs in order to realize that there needed to be a clearer integration of OERs into the assessment plan with the client. The incorporation of OERs requires a review and modification of the instructional design process. The assessment plan that was initially developed would need to be revamped in order to include an OER for assessment. ( $\mathrm{P}_{3} 8$, self-reflection)

\section{Discussion}

This qualitative inquiry tapped into $\mathrm{K}-12$ teachers' perspective, revealing their view of implementing OER. In particular, the teachers in this study underwent OEP wherein they could search, adapt, implement, and redistribute OER-based assessment. OEP are a viable option for increasing teachers' awareness of OER (Kimmons, 2016), but evidence is still needed to understand how OER can influence teachers' acceptance of and readiness to use OER (Wiley et al., 2017). Understanding these teachers' perception of OER as well as the barriers to implementing OER after participating in OEP is thus valuable: it fills the gap in the literature and also presents implications on further usage of OER in $\mathrm{K}-12$ schools.

The interpretation of the findings on the teachers' perception of implementing OER after the experience with OEP was grounded in the technology acceptance model (Davis, 1989). Specifically, OEP allowed the teachers to develop positive attitudes towards OER usage given their perceived ease and usefulness of using OER in K-12 classrooms, corroborating the findings of Tang et al. (in press). First, teachers in this research found it easy to access, use, and share OER without being restrained by copyright and cost concerns (Kelly, 2014). Second, teachers also found OER useful to improve their teaching efficiency and performance (Kimmons, 2015; 2016). OER provided a variety of resources as a base that teachers can build on to efficiently design courses and personalize instructions. Rather than creating resources from scratch, teachers can use OER with rich resources to save time in course preparation. Furthermore, the teachers attending the OEP experience were involved in an online community of educators through which they benefited from ideas shared by those with successful strategies resolving similar issues. This finding echoes Wiley and Hilton's (2018) conclusion that OEP extends the benefits of OER beyond one classroom or school district and forms a large community of open sharing, which in turn further reinforces OER adoption in K12 settings. Grounded in TAM (Davis, 1989), the findings of my study provided an alternative perspective of understanding OER acceptance in $\mathrm{K}-12$ schools. Although this inquiry cannot quantify the effectiveness 
of OEP in increasing OER acceptance, it directs a new line of inquiry to systematically understand OER acceptance in $\mathrm{K}-12$ settings (Tang et al., in press).

This inquiry of teachers' perceived barriers in OER implementation is closely aligned with seminal works by Ertmer et al. (2012) and Hew and Brush (2007). The findings of this research reviewed several firstorder barriers (e.g., a lack of high-quality resources, time, supportive climate, and support) and secondorder barriers (e.g., a lack of awareness of, proficiency in finding, and expertise in integrating ORE) that impeded the integration of OER in K-12 settings. It is worth noting some contradictions between teachers' perceived benefits and barriers. For example, a variety of resources made OER easy to use and access and were also useful for course preparation, but teachers who are not proficient in sifting through appropriate OER might view the number of options for course resources to be overwhelming. Another example is teachers' varying appraisal of open licenses of OER. Some teachers found it easy to adapt and share OER with the open licenses, but teachers without efficient awareness of OER or expertise in integrating OER might struggle to determine whether an online resource was open-licensed, which might hamper their continued usage of OER. Actually, these contradictions reinforce the need to provide tailored training and support for teachers to efficiently understand, use, and advocate for OER. For example, district-wide teacher training and a positive climate are needed to further promote using OER in K-12 schools (Kimmons, 2016).

This research offers practical implications for educators, administrators, and practitioners to improve teachers' usage of OER in K-12 setting. First, they should reinforce $\mathrm{K}-12$ teachers' awareness of OER, especially the ease of and usefulness of using OER in teaching. Second, they should provide professional development opportunities for K-12 teachers to learn how to efficiently search and adapt OER for their own classroom. One viable option is to enable OEP in professional development programs for teachers to provide a contextualized experience with OER (Kimmons, 2016; Wiley et al., 2017). Third, they should improve the quality assurance of OER. The fact that limited high-quality OER are available for $\mathrm{K}-12$ teachers thwarts the potential of OER in K-12 settings (Kimmons, 2016). Strengthening quality assurance to maintain the quality, credibility, and sustainability of OER is necessary to promote OER implementation in this setting.

This research also has some limitations. First, the research relied solely on data collected from participants in one class at the same institution in the United States. The cultural difference between different countries might also influence the interpretation of findings (Tang \& Bao, 2020). Future research might consider validating the findings of this research in multiple research sites with a large sample of participants from various cultures. Second, though I attempted to increase the validity and credibility of the findings, the limitation of qualitative research needs to be addressed (Creswell, 2007). Most of the findings were rooted in the my interpretations of the qualitative data which brought in subjectivity and inaccuracy. For future research, multiple sources of data, such as surveys, and interviews, would provide supplemental insights into teachers' perceptions of OER. 


\section{Acknowledgements}

This research was completed as a part of the OER Fellowship honored to the author by the Open Education Group. The author would like to thank Dr. John Hilton III for his support with this research. The author also thanks those students participating in this research. 


\section{References}

Blomgren, C. (2018). OER awareness and use: The affinity between higher education and K12. International Review of Research in Open and Distributed Learning, 19(2), 55-70. doi:10.19173/irrodl.v19i2.3431

Bowen, G. A. (2006). Grounded theory and sensitizing concepts. International Journal of Qualitative Methods, 5(3), 12-23. doi:10.1177/160940690600500304

Boyatzis, R. (1998). Transforming qualitative information: Thematic analysis and code development. Thousand Oaks, CA: Sage.

Braun, V., \& Clarke, V. (2006). Using thematic analysis in psychology. Qualitative Research in Psychology, 3(2), 77-101. doi:10.1191/1478088706qpo630a

Creswell, J. W. (2007). Qualitative inquiry and research design: Choosing among five traditions (2nd ed.). Thousand Oaks, CA: Sage.

Cronin, C. (2017). Openness and praxis: Exploring the use of open educational practices in higher education. The International Review of Research in Open and Distributed Learning, 18(5), 1-21. doi: $\underline{10.19173 / \text { irrodl.v18i5.3096 }}$

Davis, F. D. (1989). Perceived usefulness, perceived ease of use, and user acceptance of information technology. MIS Quarterly, 13(3), 319-340. doi:10.2307/249008

Davis F. D., Bagozzi R. P., \& Warshaw P. R. (1989). User acceptance of computer technology: A comparison of two theoretical models. Management Science, 35, 928-1003. doi: $10.1287 / \mathrm{mnsc} .35 .8 .982$

Ertmer, P. A., Ottenbreit-Leftwich, A. T., Sadik, O., Sendurur, E., \& Sendurur, P. (2012). Teacher beliefs and technology integration practices: A critical relationship. Computers \& Education, 59(2), 423435. doi:10.1016/j.compedu.2012.02.001

Fereday, J., \& Muir-Cochrane, E. (2006). Demonstrating rigor using thematic analysis: A hybrid approach of inductive and deductive coding and theme development. International Journal of Qualitative Methods, 5(1), 80-92. doi:10.1177/160940690600500107

Granić, A., \& Marangunić, N. (2019). Technology acceptance model in educational context: A systematic literature review. British Journal of Educational Technology, 5o(5), 2572-2593. doi:10.1111/bjet.12864

Hassall, C., \& Lewis, D. I. (2016). Institutional and technological barriers to the use of open educational resources (OERs) in physiology and medical education. Advances in Physiology Education, 41(1), 77-81. doi:10.1152/advan.00171.2016 
Hew, K. F., \& Brush, T. (2007). Integrating technology into K-12 teaching and learning: Current knowledge gaps and recommendations for future research. Educational Technology Research and Development, 55(3), 223-252. doi:10.1007/s11423-006-9022-5

Hilton, J. (2016). Open educational resources and college textbook choices: A review of research on efficacy and perceptions. Educational Technology Research and Development, 64(4), 573-590. doi:10.1007/s11423-016-9434-9

Hilton III, J., Larsen, R., Wiley, D., \& Fischer, L. (2019). Substituting open educational resources for commercial curriculum materials: Effects on student mathematics achievement in elementary schools. Research in Mathematics Education, 21(1), 60-76. doi:10.1080/14794802.2019.1573150

Kelly, H. (2014). A path analysis of educator perceptions of open educational resources using the technology acceptance model. The International Review of Research in Open and Distributed Learning, 15(2), 26-42. doi:10.19173/irrodl.v15i2.1715

Kimmons, R. (2015). OER quality and adaptation in $\mathrm{K}-12$ : Comparing teacher evaluations of copyrightrestricted, open, and open/adapted textbooks. The International Review of Research in Open and Distributed Learning, 16(5), 39-57. doi:10.19173/irrodl.v16i5.2341

Kimmons, R. (2016). Expansive openness in teacher practice. Teachers College Record, 118(9), 1-34. Retrieved from https://www.tcrecord.org/Content.asp?ContentId=21521

Lin, Y. J., \& Tang, H. (2017). Exploring student perceptions of the use of open educational resources to reduce statistics anxiety. Journal of Formative Design in Learning, 1(2), 110-125. doi: $10.1007 / \mathrm{s} 41686-017-0007-\mathrm{Z}$

Merriam, S. B. (1998). Qualitative research and case study applications in education. Jossey-Bass Publishers: San Francisco, CA.

Morales, R., \& Baker, A. (2018). Secondary students' perceptions of open science textbooks. Journal of Interactive Media in Education, 2018(1). doi:10.5334/jime.455.

Moustakas, C. (1994). Phenomenological research methods. Thousand Oaks, CA: Sage Publications.

Office of Educational Technology. (n.d.). \#GoOpen Districts. United States Department of Education. Retrieved from http://tech.ed.gov/open/districts/

Patton, M. Q. (2002). Qualitative research and evaluation method. (3rd ed.). Newbury Park, CA: Sage Publications.

Read, K., Tang, H., Dhamija, A., \& Bodily, B. (2020). Understanding the impact of OER courses in relation to student socioeconomic status and employment. International Journal of Open Educational Resources, 3(1). Retrieved from https://ijoer.org/understanding-the-impact-of-oer- 
courses-in-relation-to-student-socioeconomic-status-and-employment

doi:10.18278/ijoer.3.1.5

Tang, H., \& Bao, Y. (2020). Social justice and K-12 teachers' effective use of OER: A cross-cultural comparison by nations. Journal of Interactive Media in Education, 202O(1). doi:10.5334/jime.576

Tang, H., Lin, Y. J., \& Qian, Y. (in press). Understanding K-12 teachers' intention to adopt open educational resources: A mixed methods inquiry. British Journal of Educational Technology. doi:10.1111/bjet.12937

Wiley, D., \& Hilton III, J. L. (2018). Defining OER-enabled pedagogy. International Review of Research in Open and Distributed Learning, 19(4), 133-147. doi:10.19173/irrodl.v19i4.3601

Wiley, D., Webb, A., Weston, S., \& Tonks, D. (2017). A preliminary exploration of the relationships between student-created OER, sustainability, and students' success. International Review of Research in Open \& Distance Learning, 18(4), 60-69. doi: 10.19173/irrodl.v18i4.3022 


\section{Appendix}

Table 1

Summary of the Qualitative Data Analysis Results

\begin{tabular}{|c|c|c|c|}
\hline Question(s) & Theme(s) & Categories & $\begin{array}{l}\text { Sample } \\
\text { code(s) }\end{array}$ \\
\hline \multirow{3}{*}{$\begin{array}{l}\text { What are } \\
\text { teachers' } \\
\text { perceptions of } \\
\text { implementing } \\
\text { OER after } \\
\text { participating in } \\
\text { OEP? }\end{array}$} & $\begin{array}{l}\text { Participating in OEP } \\
\text { empowered teachers' } \\
\text { perceived ease of using } \\
\text { OER. }\end{array}$ & $\begin{array}{ll}\text { - } & \text { easily accessible } \\
\text { - } & \text { no costs } \\
\text { - } & \text { no copyright restrictions }\end{array}$ & $\begin{array}{l}\text { access, search, } \\
\text { save money, } \\
\text { easy, } \\
\text { copyright }\end{array}$ \\
\hline & $\begin{array}{l}\text { Participating in OEP } \\
\text { afforded teachers' } \\
\text { perceived usefulness of } \\
\text { OER. }\end{array}$ & $\begin{array}{ll}\text { - } & \text { useful resources for course design } \\
\text { - } & \text { personalized instruction } \\
\text { - } & \text { saving teachers' time } \\
\text { - } & \text { reciprocal community of educators }\end{array}$ & $\begin{array}{l}\text { base, } \\
\text { reference, } 5 \mathrm{R}, \\
\text { time-saver, } \\
\text { network, } \\
\text { collaboration, } \\
\text { sharing, } \\
\text { worldwide }\end{array}$ \\
\hline & $\begin{array}{l}\text { Participating in OEP } \\
\text { developed teachers' } \\
\text { positive attitudes about } \\
\text { implementing OER. }\end{array}$ & $\begin{array}{l}\text { - } \quad \text { positive experience } \\
\text { - continued implementation } \\
\text { - } \quad \text { agents of change" }\end{array}$ & $\begin{array}{l}\text { like, enjoy, } \\
\text { valuable, use, } \\
\text { sharing, } \\
\text { advocates, } \\
\text { support }\end{array}$ \\
\hline \multirow[t]{2}{*}{$\begin{array}{l}\text { What are } \\
\text { teachers' } \\
\text { perceived barriers } \\
\text { towards } \\
\text { implementing } \\
\text { OER in K-12 } \\
\text { settings? }\end{array}$} & $\begin{array}{l}\text { First-order barriers of } \\
\text { implementing OER }\end{array}$ & $\begin{array}{l}\text { - } \quad \text { lack of quality assurance } \\
\text { - limited time } \\
\text { - } \quad \text { unsupportive climate } \\
\text { - inadequate support }\end{array}$ & $\begin{array}{l}\text { resources, } \\
\text { colleges, } \\
\text { school district, } \\
\text { unaligned, } \\
\text { missing, } \\
\text { outdated, } \\
\text { validated }\end{array}$ \\
\hline & $\begin{array}{l}\text { Second-order barriers of } \\
\text { implementing OER }\end{array}$ & $\begin{array}{l}\text { - } \quad \text { a lack of awareness of OER } \\
\text { - a lack of proficiency in finding } \\
\text { OER } \\
\text { - a lack of expertise in integrating } \\
\text { OER }\end{array}$ & $\begin{array}{l}\text { awareness, } \\
\text { why to use, } \\
\text { finding, } \\
\text { searching, } \\
\text { matched, } \\
\text { integrating }\end{array}$ \\
\hline
\end{tabular}

